\title{
El deber de enrolarse y el derecho a votar. Reflexiones en torno a la ciudadanía armada y el sufragio en argentina, 1863-1877 ${ }^{1}$
}

\author{
por \\ Flavia Macías \\ (Instituto Ravignani/PEHESA -CONICET) \\ flamac00@gmail.com
}

El presente trabajo reflexiona sobre uno de los temas clave de la historia politica decimonónica hispanoamericana: el papel de las fuerzas cívico militares, en particular la Guardia Nacional, en los procesos electorales y sus efectos en la construcción de la ciudadanía política. En particular, se concentra en la Argentina de las décadas de 1860 y 1870 y explora de qué manera las leyes y las instituciones definieron y delimitaron la relación entre el enrolamiento en la Guardia Nacional y el ejercicio del derecho a voto. Para ello se estudian los debates legislativos previos a la puesta en vigencia de la Ley Electoral Nacional de 1863 y los relativos a las reformas electorales de 1873 y 1877, así como los cambios en la legislación electoral y las influencias del pensamiento de Domingo Faustino Sarmiento en los referidos procesos.

Palabras Clave: Guardia Nacional; elecciones; ciudadanos en armas; republica.

Buena parte de la historiografía latinoamericana se ha encargado de revisar el papel de la Guardia Nacional en la vida política decimonónica. El avance de estas investigaciones abrió todo un campo de estudio centrado en el análisis y la reinterpretación del rol de la violencia en la construcción republicana del siglo XIX, en especial, en la configuración institucional y del poder político. Las tensiones y disputas en torno a la legítima capacidad de

\footnotetext{
${ }^{1}$ Investigación realizada bajo el proyecto I+D HAR2013-42563P. Una primera versión de este trabajo en las Jornadas Elecciones en la Argentina (siglos XIX y XX), Buenos Aires, UNSAM, 2012. Agradezco los comentarios de Marcela Terajavasio.
} 
organizar y movilizar fuerzas por parte de los gobiernos o de empuñar las armas por parte de los ciudadanos constituyen cuestiones cuyo abordaje ha permitido contribuir con nuevas explicaciones respecto del problema de las incumbencias militares, la definición y el ejercicio de los deberes y derechos individuales y el papel de las armas en la construcción republicana y en las prácticas políticas ${ }^{2}$. En especial, adquirió relevancia el interés general por explicar el papel de la Guardia Nacional en los procesos electorales y, asimismo, en la construcción de la ciudadanía política. El presente trabajo ensaya una reflexión sobre esta cuestión en la Argentina de las décadas de 1860 y $1870^{3}$. El objetivo es interpretar aquellos caminos tomados por las leyes, los reglamentos ${ }^{4}$ y las instituciones militares y de orden público para definir y a su vez delimitar el vínculo entre el enrolamiento en la Guardia y el ejercicio del derecho a voto a partir de la reformas electorales de 1863 y 1877. En esos a años el mencionado vínculo se cristalizó - tanto desde el punto de vista reglamentario como desde la práctica- $\mathrm{y}$, asimismo, fue motivo de debates y controversias que implicaron la convivencia y puesta a prueba de diferentes maneras de comprender y practicar la ciudadanía. Este trabajo se propone reflexionar, en primer lugar, sobre el vínculo entre deberes y derechos militares y electorales de los ciudadanos argentinos luego de la reforma electoral de 1863, en la que se estableció la necesidad de estar enrolado en la Guardia Nacional para poder votar. También se retoman algunos avances y conclusiones en torno a la relación Guardia Nacional y prácticas políticas -ya abordados en otros trabajos- a partir de la promulgación de esta ley. Luego se pone especial atención en las reformas propuestas por Domingo Faustino Sarmiento a partir de su presidencia (1868-1874). Se explora el impacto que las mismas generaron en la noción de ciudadanía en armas, en el funcionamiento militar y electoral -en particular respecto de la relación Guardia Nacional/eleccio-

2 Guy Thomson, 1990. Hernández Chávez, 1994. Graham, 1995. Deas, 1997. Sábato, 1999. Chust y Marchena, 2007. Bonaudo, 2005. Carvalho, 1995. Irurozqui, 2000. Malamud y Dardé, 2004. Méndez, 2005, entre otros.

${ }^{3}$ En la Argentina, la Guardia Nacional constituyó la gran milicia nacional que, además organizarse como complemento del Ejército de Línea y sobre la base del principio de ciudadanía en armas (al igual que en el resto de Hispanoamérica), tuvo por función reemplazar al antiguo sistema miliciano local-provincial sobre el que se sostuvieron la gran mayoría de los Ejércitos Provinciales en las décadas previas a la organización nacional. El reemplazo de los tradicionales cuerpos de milicias -adscriptos a parámetros locales y personales y con fuerte arraigo en la figura del gobernador- fue más rápido en algunas provincias que en otras, planteándose la convivencia entre estos tradicionales regimientos y los nuevos batallones de la Guardia Nacional (Macías, 2014).

${ }^{4}$ Sobre reformas electorales en la segunda mitad del siglo XIX, Malamud, 2000. Navajas, 2008. 
nes- y en los debates parlamentarios que, previo a las reformas electorales de 1873 y 1877, se desarrollaron en torno a la directa relación entre el deber de enrolamiento y el ejercicio del sufragio.

\section{CiUdadAnOS EN ARMAS Y VOTANTES}

Con la firma de la Constitución Nacional de 1853 se inició un arduo proceso de institucionalización que implicó, entre otras tareas, la creación de normas y códigos para reordenar el funcionamiento de las provincias firmantes, en el marco del nuevo escenario político con vocación nacional ${ }^{5}$. En materia de ciudadanía, las provincias adscribieron al principio amplio y aglutinante que formularon la Carta Magna y la posterior Ley de Ciudadanía de 1857: «... son ciudadanos los mayores de 21 años o antes si fuesen emancipados y... los extranjeros que el 9 de Julio de 1853 eran ya reputados ciudadanos en cada provincia $»^{6}$. Los comicios y su funcionamiento nacional y provincial fueron objeto de normativas específicas, que también se elaboraron en concordancia con la Constitución y la referida ley ${ }^{7}$. La edad y la nacionalidad fueron los únicos requisitos que definieron al elector de la Argentina de la segunda mitad del siglo XIX y todas las provincias adaptaron sus leyes a este principio. Sin embargo a partir de 1863, luego de la incorporación de Buenos Aires al contexto nacional, se estipuló otro requerimiento más: la necesidad de estar enrolado en la Guardia Nacional ${ }^{8}$. A partir de la reforma electoral de ese año, la inscripción de cada ciudadano en el Registro Cívico (documento en el que debían registrarse para poder votar) dependía de la posesión de la papeleta de enrolamiento en la Guardia Nacional. La institucionalización de este reque-

${ }^{5}$ Sobre el proceso general, Sábato, 2012.

${ }^{6}$ En el artículo $20^{\circ}$ de la Constitución se aclara que los extranjeros gozan en el territorio de la Nación de todos los derechos civiles del ciudadano no estando obligados a admitir la ciudadanía ni a pagar contribuciones forzosas extraordinarias. Obtenían la nacionalización residiendo dos años continuos en la Confederación. "Constitución Nacional de 1853", Registro Oficial de la República Argentina, 1883, tomo IV: 66.

${ }^{7}$ Hasta la puesta en vigencia de la Ley Nacional de Elecciones de 1857, fueron las leyes y reglamentos provinciales los que rigieron los comicios.

${ }^{8}$ Luego de la Batalla de Caseros (1852) se inició el proceso de organización nacional. Buenos Aires y las provincias no llegaron a ponerse de acuerdo, entre otros puntos, sobre el tema de la capital federal. Finalmente, Buenos Aires se constituyó en estado independiente y declararon, en 1854, su propia constitución. Luego de 1862, se unió al proyecto nacional y su gobernador, Bartolomé Mitre - miembro del partido nacionalista porteño- fue designado y luego electo presidente de la nación. Para un análisis de estos temas véanse Halperín, 1982. Oszlak, 1997. Sabato, 2012. 
rimiento nos lleva a reflexionar sobre varias cuestiones. Por una parte, sobre la base de qué principios se estipuló esta articulación entre deberes militares y derechos electorales de los ciudadanos. Por otra, como se pensó y reguló el papel de la Guardia Nacional en relación con las elecciones. Por último, de qué manera se visibilizaron los efectos de esta normativa en la práctica política ${ }^{9}$.

\section{Los debates y las leyes}

Los debates de la cámara de diputados de la nación en torno a los procedimientos electorales dieron origen, entre otras, a la Ley Electoral Nacional de 1857 y a sus posteriores reformas ${ }^{10}$. En cuanto a la definición del votante, la edad y la nacionalidad argentina fueron los referentes fundamentales y sobre esto hubo acuerdos generalizados. Los debates sobre esta ley y sus reformas de 1859 y 1863 se desarrollaron en torno a la naturalización de extranjeros y su consecuente adquisición de derechos políticos y, asimismo, en relación con las razones de pérdida o suspensión de ciudadanía. Otro de los temas centrales fue la confección del Registro Cívico y los instrumentos que para este fin debían motorizarse ${ }^{11}$. Este registro fue un instrumento que se implementó para inscribir a los votantes y formar un padrón electoral que permitiera la organización de los comicios. La inscripción era voluntaria -al igual que el voto- pero necesaria para poder sufragar ${ }^{12}$. Mediante la expedición de una boleta que funcionaba como constancia, se acreditaba la condición de elector. El padrón, confeccionado tiempo antes de las elecciones en cada

9 Sobre esta última cuestión hemos desarrollado trabajos que refieren al caso de Tucumán, en complemento con investigaciones desarrolladas para otras provincias. Macías 2007; 2011; 2011a; 2014. Macías y Parolo, 2010. Macías y Sábato, 2013. Macías y Navajas 2015. En el presente trabajo, referiremos a algunos ejemplos pero solo a titulo ilustrativo ya que, en este caso, pretendemos centrar la atención en los debates y argumentos discursivos que rodearon la elaboración de la legislación y el funcionamiento institucional electoral y militar así como la relación entre ciudadanía en armas y votantes. Sobre las practicas electorales en la Argentina se ha desarrollado una amplia historiografía. Un trabajo que articula sus resultados y conclusiones es el de Sabato, Ternavasio, De Privitellio y Persello, 2011.

${ }^{10}$ Diarios de Sesiones de la Cámara de Diputados, Archivos Legislativos (Argentina), Honorable Cámara de Diputados de la Nación, años 1857-1879, libros 5 a 12.

11 Ibidem, libro 5, tomo 2.

12 Recordemos que en la Argentina del siglo XIX, al igual que en el resto de Hispanoamérica, el voto se concibió como un derecho, es decir como un componente central e inherente a la ciudadanía política. Al respecto, Annino, 1995. Posada Carbó, 1997. Sabato y Lettieri, 2003. Malamud y Dardé, 2004. Irurozqui, 2005; 2005a. Bragoni y Miguez, 2010. Sabato, Ternavasio, De Privitellio y Persello, 2011. 
provincia por una junta calificadora (constituida por el municipio o parroquia) llegaba a manos de la mesa central escrutadora y luego era devuelto a la entidad inscriptora, donde se conservaba este original ${ }^{13}$. En el año 1859 se desarrollaron nuevos debates que plantearon una gran preocupación por parte de los diputados respecto de las maneras de hacer efectiva la inscripción en dicho registro y respecto de aquellas pruebas que demostraran que el individuo registrado gozaba de los requisitos necesarios para ser un elector. Los intercambios en torno a las formas de confeccionar un registro lo más amplio y verídico posible tuvieron que ver con la necesidad de garantizar un electorado lo suficientemente numeroso y fiel a la Ley de Ciudadanía, para otorgar legitimidad al acto eleccionario. En 1863, la nueva reforma electoral volvió sobre la complicada confección del Registro Cívico y fue en ese marco que se incorporó un nuevo requisito para el empadronamiento, la acreditación de enrolamiento en la Guardia Nacional: "Artículo $6^{\circ}$ : no podrán inscribirse en el Registro Cívico los menores de 18 a menos de estar enrolados en la Guardia Nacional, los dementes, los sordomudos, los eclesiásticos regulares, los soldados cabos y sargentos de tropas de línea, y los que debiendo estar enrolados en la Guardia Nacional con arreglo a la ley, no lo estuviese» ${ }^{14}$. El enrolamiento en la Guardia era un deber ciudadano y fue su padrón el que se convino como antecedente directo del Registro Cívico. A partir de la referida reforma cada ciudadano, para poder inscribirse y luego votar, debía estar en posesión de la papeleta de enrolamiento en la Guardia Nacional. Este nuevo ordenamiento pareció otorgar a los inscriptores la posibilidad de utilizar un documento institucional/militar que acreditaba la condición de ciudadano de quienes asistían a inscribirse $\mathrm{y}$, de igual manera un conocimiento, lo más cercano posible, de la población electora ${ }^{15}$. Asimismo, amplió el universo de

${ }^{13}$ Ley de Elecciones de 1857 - Capítulo II - Artículos 2 a 17, Diarios de Sesiones, Archivos Legislativos, Honorable Cámara de Diputados de la Nación, libro 5, tomo 2, f. 253-288, 1857.

${ }^{14}$ Ley de Elecciones de 1863, Capitulo 2, Artículo 6, Diarios de Sesiones, Archivos Legislativos, Honorable Cámara de Diputados de la Nación, libro 11, f. 138v.

${ }^{15}$ Este requerimiento fue previamente puesto a debate en las sesiones de agosto de 1863 destinadas a discutir y reformar algunos puntos de la Ley de Ciudadanía de 1857, en especial, lo relativo a si la ciudadanía podía perderse o no -o simplemente suspenderse- y cuáles eran las potenciales razones para que esto ocurriera. En ese contexto, Adolfo Alsina (diputado por Buenos Aires) propuso reproducir los principios plasmados en la Constitución del Estado de Buenos de 1854 que en su artículo 12 afirmaba que una de las razones de suspensión de la ciudadanía era la no inscripción en la Guardia Nacional. (Sesiones ordinarias del 19, 24 y 26 de Agosto de 1863, Diario de Sesiones, Archivos Legislativos, Honorable Cámara de Diputados de la Nación, libro 12). Esta propuesta fue rechazada en relación a la Ley de Ciudadanía pero fue luego reformulada e incorporada como requisito ineludible para la emisión del voto, en el marco de la reforma electoral nacional de 1863. 
electores a aquellos individuos varones menores de 18 años que acreditaran inscripción en la Guardia Nacional ${ }^{16}$.

Analicemos, en primer lugar, que significaba estar enrolado en la Guardia Nacional. Desde la organización de esta fuerza cívico-militar, el enrolamiento en la misma fue planteado como un compromiso cívico: «... considerando: que la defensa de la Patria y de las instituciones es un deber sagrado de todo argentino, como también el medio más positivo de afianzar el orden, las leyes, las garantías de los ciudadanos, y los benéficos resultados que debe producir un esfuerzo común y nacional cuando la necesidad lo hiciere preciso... (El Poder Ejecutivo Nacional) decreta: todo ciudadano de la Confederación Argentina desde la edad de 17 años hasta los 60 está obligado a ser miembro de alguno de los cuerpos de Guardias Nacionales, que las provincias confederadas deben crear con la brevedad posible» ${ }^{17}$. El objetivo fue constituir una reserva del Ejército de Línea en cada provincia argentina por orden y decreto del Poder Central liderado, en ese tiempo por Justo Jose de Urquiza. Según este decreto, fueron los gobernadores los encargados de formar, ordenar y entrenar esta fuerza ${ }^{18}$. Se constituyó así un Ejército Nacional que combinaba dos maneras distintas de comprender la defensa: la Guardia Nacional basada

${ }^{16}$ En provincias como Tucumán, por ejemplo, donde la edad de enrolamiento en la Guardia comprendía a individuos de hasta 16 años, la emisión de sufragio fue un derecho que teóricamente se hizo extensivo a todos ellos: «Considerando que por lo dispuesto en el artículo 4 del decreto del 5 del presente, mandando organizar la Guardia Nacional, al determinar que desde la edad de 20 años obliga al servicio militar activo, excluye contra la intención del Gobierno, una porción de jóvenes útiles para tomar las armas, que por otra parte quieren y desean pertenecer a la guardia nacional...Art. $1^{\circ}$. El servicio activo de la guardia nacional comprende a todos los ciudadanos desde la edad de 16 años hasta la de 50». Tucumán, Mayo 19 de 1854. Cordeiro y Viale, 1915, tomo 1: 1916-70.

17 "Decreto presidencial", Registro Oficial de la República Argentina, 1883, tomo III, $1883,109$.

${ }_{18}$ Si bien la Guardia estaba subordinada al Ejecutivo Nacional, al igual que toda fuerza militar de la nación, la organización de la misma fue provincial. Esto otorgó mucho poder a los gobernadores sobre esta institución, sumado a que eran ellos quienes elegían la mayor parte de sus altos escalafones (más allá del principio eleccionario que figuraba en su decreto de organización: «Será atribución exclusiva del gobierno el nombramiento del jefe principal de cada cuerpo. En todo lo demás, la elección de oficiales y clases se hará en la forma siguiente: cada compañía elegirá directamente sus clases hasta el cargo de sargento $2^{\circ}$., inclusive los cabos y sargento de cada compañía, unidos a diez diputados nombrados por ella, elegirá sus oficiales hasta la clase de capitán. Los oficiales del batallón elegirán el Sargento Mayor y el Comandante del cuerpo»). Cordeiro y Viale, 1915, tomo 1: 1916-66. La movilización y control de esta fuerza fue disputada por los gobernadores y poder central, en el marco de una problemática que atravesó el proceso de construcción nacional: el control de la violencia. Macías y Sábato, 2013. 
en el principio de la ciudadanía en armas y el Ejército de Línea, ligado a una noción regular y profesional del servicio militar ${ }^{19}$.

Para ser Guardia Nacional los requisitos eran los mismos que aquellos impuestos por la Ley de Ciudadanía de 1857 es decir, la edad y la nacionalidad ${ }^{20}$. Los comandantes de cada regimiento o batallón organizado en cada localidad de cada provincia debían elaborar el mencionado padrón de enrolamiento $\mathrm{y}$, de igual modo, debían entregar a cada guardia nacional su comprobante de inscripción. De esta manera, el padrón de la Guardia ofrecía la nómina ciudadana que, además de cumplir con los requisitos estipulados por la Ley de Ciudadanía y la Constitución, demostraba el cumplimiento de uno de los compromisos esenciales -constituido en deber primigenio- de la ciudadanía: el enrolamiento en la Guardia.

La Guardia Nacional, por sus principios fundacionales y su normativa interna, representaba a la ciudadanía en su esencia, es decir, a los individuos que, respetuosos de la Carta Magna y de las instituciones republicanas, asumían también su custodia mediante el acto de enrolamiento y la disposición de movilizarse cuando las autoridades y las coyunturas así lo requirieran: «...la guardia

19 En la tradición republicana incorporada por las regiones hispanoamericanas luego de la ruptura colonial, el problema de la defensa y de quiénes debían estar a cargo de la misma constituyó una cuestión central. En ese marco emergieron dos convicciones: una de ellas sostenía que sólo los miembros de la comunidad, sus ciudadanos, debían formar las fuerzas armadas, y que recurrir a ejércitos de soldados pagos («mercenarios») abría el camino a la pérdida de la libertad y la tiranía. Esta convicción, que se articulaba con un conjunto más amplio de ideales y representaciones republicanas, era discutida por quienes sostenían que la mayor eficacia de las fuerzas profesionales frente a las necesidades empíricas de la guerra. Las nuevas repúblicas hispanoamericanas recurrieron tanto a la ciudadanía armada como a la formación de ejércitos regulares y la complejidad inherente a estas fuerzas y su funcionamiento residió en gran medida en esta combinación (Macías y Sábato, 2013). Véanse algunos ejemplos de estas tensiones en: Chust y Marchena, 2007. Irurozqui y Galante, 2011. Garavaglia et al., 2012. Para un análisis historiográfico sobre las producciones en torno a la organización y funcionamiento militar y político de las milicias locales y la Guardia Nacional en la Argentina del siglo XIX, véase Canciani, 2012.

${ }^{20}$ Según el referido decreto, quedaban exceptuados del servicio activo los ministros del Poder Ejecutivo Nacional, los miembros del Congreso, gobernadores de provincias, miembros de las Legislaturas provinciales, jueces de los Tribunales nacionales y provinciales y los que tenían imposibilidad legalmente aprobada. Quedaban dispensados del servicio los directores y rectores de las universidades, los Jefes de oficina de la nación y de la provincia, maestros de Posta, médicos y practicantes, boticarios, los que aún no habían cumplido los 18 años, y el hijo único de madre viuda. Quedaban también exentos del servicio militar obligatorio los empleados y alumnos del Colegio Montserrat. Todo individuo con capacidad para enrolarse en la Guardia Nacional que no lo hacía, era destinado a servir tres años en el Ejército de Línea. La inasistencia a sorteos o a ejercicios doctrinales eran penados con multas intercambiables por días de prisión. 
nacional es en la máquina de los gobiernos republicanos, el gran moderador que asegura a un tiempo el orden y la libertad, manteniendo dentro de justos límites la autoridad y la personalidad... ${ }^{21}$. Edificada sobre estos principios, la Guardia materializaba el compromiso que la Constitución Nacional demandaba a la ciudadanía en su artículo $21^{\circ}$ : «todo ciudadano debe armarse en defensa de la Patria y de esta Constitución». Además de imprimirse en toda legislación sobre la Guardia, estos fundamentos se difundieron en actos cívicos y discursos oficiales que, pronunciados en momentos emblemáticos y conmemorativos, se reproducían luego en la prensa local en cada provincia argentina: "Guardias nacionales, ciudadanos: El día de hoy es el más grande aniversario de la patria. Quiera pues el cielo que la posteridad os deba el reconocimiento a vosotros que sois la Patria de hoy, de haberles transmitido sin manchas el estandarte que os enseña y conduce a establecer el imperio de la libertad y de las leyes. A estas instituciones debéis tener en vuestras manos la fuerza y el poder para conservarlas incólumes [siendo] las primeras y más sagradas garantías que debe tener el hombre en sociedad. Tenéis la dignidad y el patriotismo y esto basta porque el patriotismo germinará el valor que os hará invencibles» ${ }^{22}$.

Luego de la sanción de Ley Electoral de 1863, el deber patriótico-militar materializado, en primera medida, en el enrolamiento, terminó por anteceder al voto y determinó su expedición. Este recurso instrumental colaboró con el proceso electoral pero también con la consolidación de una noción de ciudadanía en la que el enrolamiento en la Guardia y los atributos del «ciudadano armado» pasaron a ocupar un lugar central en la configuración de la comunidad política. Asimismo, la institución cívico-militar, su organización y sus principios parecieron incorporar una noción de ciudadanía que definió a los guardias nacionales como garantes del orden público y el funcionamiento de la república: «...la subordinación y orden que observa la Guardia Nacional se ha convertido en la mejor garantía de la tranquilidad pública. Todos sus jefes, oficiales y soldados se han hecho dignos de la estimación del gobierno» ${ }^{23}$. El enrolamiento en la Guardia pasó a constituirse en un componente casi natural de la ciudadanía cuyo incumplimiento se asociaba con la carencia de una virtud patriótica, situación que ponía en duda la capacidad del individuo de salvaguardar la comunidad política y sus instituciones y, por lo tanto, de ejercer el derecho a voto.

${ }^{21}$ Reglamento sobre infractores de la Guardia Nacional. Tucumán, Julio 18 de 1860, Cordeiro y Viale, 1915, tomo 1: 277.

22 Discurso del comandante en jefe del Batallón Belgrano de la provincia de Tucumán Fiesta cívica del 9 julio, Diario Eco del Norte, 10 de julio de 1859. Macías, 2014: 93.

${ }_{23}$ Discurso del Gobernador Marcos Paz a la Legislatura tucumana, año 1858, Cordeiro y Viale, 1915, tomo II: 1916-305 
Es interesante destacar que la relación entre enrolamiento y derecho a voto se estipuló específicamente a través del enrolamiento en la Guardia Nacional y no del Ejercito de Línea, institución que acuñaba una noción profesional de la defensa. Los miembros de tropa vieron limitadas sus acciones en el escenario comicial. Los soldados del Ejército de Línea, en ninguno de sus escalafones (sargentos, cabos y soldados) podían emitir voto más allá de que gozaran plenamente de sus derechos civiles ${ }^{24}$. La referida limitación se complementó con la reproducción de otra preexistente: «quedan prohibidos los armamentos de tropa o cualquier otra ostentación de fuerza armada y aún la citación de milicias en el día de la recepción del sufragio» ${ }^{25}$. De esta manera la Ley Nacional intentó poner freno a las fuerzas de línea asociadas a un servicio regular y profesional y pero también a los antiguos cuerpos de milicias locales y sus comandantes respecto de las influencias que normalmente efectuaban el día de los comicios a través de sus rangos. En las leyes provinciales, estas especificaciones fueron incorporando detalles, llegándose a explicitar, por ejemplo, que se prohibía a comandantes, jefes y oficiales de milicias «asistir a la mesa para presenciar la votación de sus subalternos»; «acaudillar gente en el acto de elección»; manipular las boletas de inscripción (dirigido a las autoridades inscriptoras) y «llevar armas a la mesa electoral... las autoridades mismas no podrán emplearlas sino a requisición de los que presidan la elección....» ${ }^{26}$. Al hacer referencias a las «milicias», las normas nacionales y provinciales señalaban a las fuerzas tradicionales y residuales locales de los Ejércitos Provinciales asociadas con revueltas organizadas en sociedad con comandantes, partidos y candidatos desfavorecidos por el resultado de alguna contienda electoral, y que, asimismo, utilizaban sus redes para convocar a los votantes, direccionar el voto y modificar un resultado electoral ${ }^{27}$.

La referida legislación demuestra que la participación de las fuerzas cívico militares en la contienda electoral es de larga data en el Río de la Plata, al igual que ocurrió en Hispanoamérica decimonónica ${ }^{28}$. Las milicias revolucionarias fueron convocadas a asambleas populares para legitimar elecciones guber-

${ }^{24}$ En el Ejército de Línea convivían soldados con individuos cumpliendo penas o castigos.

${ }^{25}$ Ley de Elecciones de 1863, Capítulo 10, Artículo 53, Diario de Sesiones de la Cámara de Diputados, Archivos Legislativos, Honorable Senado de la Nación, libro 12.

26 Véase, por ejemplo, la constitución de Córdoba del año 1870. Cucchi, 2015.

${ }^{27}$ Véase por ejemplo, el caso estudiado en Macias y Navajas, 2015. Allí analizamos el rol de los tradicionales comandantes departamentales en la organización de un levantamiento armado que pretendió desbancar al gobernador electo.

${ }^{28}$ Véanse, entre otros, Thompson, 1990. Graham, 1995. Peralta Ruiz, 1999. Hernández y Chávez, 2007. Sobrevilla, 2007. Chust y Marchena, 2007. Sabato, 2008. Irurozqui, 2009. Macías, 2014, Cucchi, 2015. Para Brasil, véase, De Castro, 1979. Carvalho, 1995. Fertig, 2010. 
namentales o bien decisiones de los cuerpos legislativos desde los primeros años de la década independentista ${ }^{29}$. Con la posterior formación de los Estados provinciales, el vínculo entre milicias, política y elecciones se afianzó, y la pieza clave en este vínculo fue el comandante. Tradicionalmente, estos jefes militares locales, provenientes en su gran mayoría de las fuerzas revolucionarias residuales, lideraron cada distrito de provincia en el que se organizaba una fuerza integrante del Ejército Provincial. Colaboraron centralmente en la configuración del poder del gobernador y, en ese marco, asumieron diferentes tareas. Tenían a su cargo diversas funciones (amparadas en la normativa provincial o en decretos del poder ejecutivo) y una de las fundamentales era el enrolamiento. El control de estas fuerzas por parte de los comandantes era fundamental en tiempos electorales. Eran ellos quienes, además de poseer una noción bastante certera de los potenciales electores, podían influir tanto en su asistencia a los comicios como en la orientación de su voto ${ }^{30}$.

Reorganizadas las provincias luego de la declaración de la Constitución Nacional de 1853, los comandantes militares locales mantuvieron un lugar central en la organización de los procesos electorales, en el armado de candidaturas y en el desarrollo de los comicios. Es decir, la construcción del poder y su legitimidad estaba íntimamente ligada a estos actores quienes participaron centralmente de la configuración y funcionamiento del Estado provincial y ahora de su reorganización e institucionalización en el marco del nuevo esquema nacional. Como demostramos en otros trabajos, la propia definición de una candidatura y el posterior sostenimiento de un gobernador en el poder no sólo implicaban gestiones a nivel de la Legislatura provincial. Los comandantes locales, constituidos en autoridad distrital, estaban a cargo del funcionamiento militar y electoral de cada localidad que integraba el territorio provincial ${ }^{31}$. Controlaban la organización de cada milicia rural y asimismo, su funcionamiento militar pero también político. Los comandantes siguieron garantizando

\footnotetext{
29 Tío Vallejo, 2000. Di Meglio, 2006. Ternavasio, 2002; 2009. Bravo, 2000; 2003.

${ }^{30}$ Los comandantes también tenían asignada la captura desertores, el levantamiento de inventarios, la ejecución de confiscaciones de bienes, la confección de información sumaria y la ejecución de penas dispuestas, muchas veces, por ellos mismos. Muchos comandantes estrecharon fuertes vínculos con el gobernador de turno mediante la configuración de una amplia y consolidada red vincular y de un sistema de reciprocidades políticas y económicas que los erigió en la mano derecha del poder ejecutivo. Otros demostraron carreras político militares destacables como las de Celedonio Gutiérrez en Tucumán, Juan Manuel de Rosas en Buenos Aires o Justo José de Urquiza en Entre Ríos, quienes llegaron a ocupar el cargo de gobernador. Véanse, entre otros, Schmit, 2004. Parolo, 2003: 175-198. Fradkin, 2010: 293-306. Macías, 2010. Lanteri, 2013. Macías y Navajas, 2015.

31 Macías y Parolo, 2010. Macías y Navajas, 2015.
} 
la participación de los electores en el acto comicial, la orientación de su voto y el orden (o no) de la votación. De hecho, muchas de los conflictos en torno a procesos electorales o a sus resultados se vincularon con enfrentamientos entre los propios comandantes, cada uno de ellos afines a diferentes candidaturas. La actividad negociadora de los gobernadores provinciales pareció profundizarse y complejizarse luego de 1853, momento en el que trató de cercar las atribuciones de los comandantes departamentales pero sin por esto quitarles el importante rol político y electoral que poseían ${ }^{32}$. Es decir, si bien se mantuvo el importante rol electoral y político desempeñado tradicionalmente por los comandantes, trató de legislarse -al igual que en la normativa nacional- respecto de la acciones armadas de las milicias en los comicios y ponerles límites ${ }^{33}$.

Más allá de todos estos señalamientos incorporados en la legislación nacional y de las provincias, la Guardia Nacional pareció exenta de todos ellos. Sus integrantes podían ser convocados en días de elecciones para cumplir con tareas de policía, si bien este llamamiento no implicaba necesariamente limitaciones explícitas para ejercer su derecho a voto ${ }^{34}$. Es decir que, por una parte, en un intento por controlar las movilizaciones armadas que tradicionalmente acompañaron los actos electorales se reguló el papel en los comicios de las fuerzas de línea y de las antiguas milicias locales. Sin embargo, la Guardia pareció concebirse como la fuerza cívico militar que por sus características y composición proveería a los comicios de votantes así como de custodios garantes de su desarrollo y ejecución.

\section{Guardia Nacional y política}

Como señalamos en el apartado anterior, la Guardia pareció exenta de aquellos señalamientos indicados para soldados y milicias locales. Sin embargo,

32 En algunos casos como el de Córdoba, Mendoza, Tucumán o Buenos Aires, el proceso fue controvertido pero finalmente exitoso. En otros casos como el de Corrientes, los comandantes manifestaron un nutrido poder a nivel local por décadas, debilitando la figura del Ejecutivo Provincial. Véase, Buchbinder, 2004.

${ }^{33}$ Luego de la llamada Revolución de los Posse (1856), se sanciono en Tucumán la Constitución provincial. La misma incorporó un artículo que precisaba que cualquier disposición tomada por «el Gobierno o la Sala de Representantes, a requisición o influencia de fuerza armada, o de una reunión de pueblo» se consideraba es nula de derecho y, por lo tanto, no debía ejecutarse (Art ${ }^{\circ} 11$ de la Constitución provincial de 1856, Cordeiro y Viale, 1915, tomo I: 383).

${ }^{34}$ Cfr. Sábato y Lettieri, 2003. Bonaudo, 2003. Bragoni y Míguez, 2010. Macías, 2014. Cucchi, 2015. 
sus principios, composición y organización local la acercaron rápidamente al juego político de cada provincia, como se ha encargado de demostrar la actual historiografía especializada en diferentes casos locales ${ }^{35}$. Incorporaremos aquí referencias a Tucumán, en el Norte argentino, como uno de los casos en los que puede observarse la rápida e íntima relación adquirida entre la Guardia Nacional y la vida pública en esas décadas.

La politización de la Guardia Nacional se articuló con el funcionamiento de los clubes y de la prensa como actores políticos: «...desde el día antes de las elecciones los jefes de la Guardia Nacional habían citado a estos a pesar de la absoluta prohibición de la ley... La mesa presenció la coacción que se ejercía sobre la Guardia Nacional» ${ }^{36}$. Salustiano Zavalía, en su cargo de gobernador de Tucumán, expresaba al respecto: «el gobernador mira con desagrado que se hiciera uso de la fuerza para inducir a ningún individuo de la Guardia Nacional a votar por una lista o abstenerse de votar por otra en los comicios electorales... esto no impide que pueda usarse la insinuación amistosa y el convencimiento que son medios de influencia con la libertad individual...» ${ }^{37}$. En ese mismo escenario, los guardias nacionales afectados a tareas de policía en días de elecciones provinciales y nacionales pasaron a constituir un arma de doble filo: por un lado- y ante un Departamento de Policía aún escuetoera la ciudadanía en armas que, constituida en fuerza pública, debía velar por el orden en los comicios pero, por otra parte, incluía individuos que, a la luz de las mencionadas denuncias, podían estar actuando en sociedad con alguno de los partidos en pugna. Otra de las cuestiones que señalamos en particular en el marco de nuestras investigaciones es la manera en la que los distintos gobiernos provinciales intentaron manejar esta fuerza mediante el control de sus altos escalafones desde donde, asimismo, salieron futuros diputados e incluso gobernadores. Uno de los casos emblemáticos en Tucumán fue el de Wenceslao Posse, quien en 1865 fue designado comandante del Batallón Mitre de guardias nacionales y destinado a asistir a las fuerzas de línea en la guerra del Paraguay y luego electo gobernador a principios de 1867: «Acepto

${ }^{35}$ Cfr. Bibliografía citada en notas anteriores.

${ }^{36}$ El Eco del Norte, 19 de Agosto de 1860. La ley electoral provincial establecía que los jefes militares no debían «permanecer en el recinto de las Asambleas electorales más tiempo que el necesario para sufragar, como así mismo encabezar grupos de ciudadanos durante la elección y hacer valer en cualquier manera la influencia de sus cargos para coartar la libertad del sufragio». La sanción que se establecía era una multa de $\$ 150$ o 45 días de prisión. Asimismo, prohibía »desde el día de la convocatoria para la elección hasta que aquella haya tenido lugar, e igualmente los armamentos de tropa o cualquier otra ostentación de fuerza armada en el día de la recepción del sufragio».

${ }^{37}$ Eco del Norte, 17 de Enero de 1860. 
gustoso el favor que el gobierno me hace elevándome a ese puesto de honor. El momento en que es necesario el desagravio por las armas del ultraje hecho a nuestra bandera por el déspota del Paraguay ningún argentino sin mengua a su forma puede mantenerse tranquilo en el hogar doméstico... Que la hora de la prueba llegue para ofrecer mi vida a la Patria en el puesto en que el gobierno de la provincia me ha señalado...» ${ }^{38}$. Para los futuros candidatos, el paso por la Guardia no solo implicaba la práctica más genuina todo aquello que alcanzaba la noción de ciudadanía sino la posibilidad de estar en contacto con quienes otorgaban sentido y legitimidad al acto eleccionario: los votantes.

Por otra parte, hemos señalado de qué manera la ciudadanía también fue apropiándose de esta institución y denunció al gobierno de turno por su utilización con fines electorales. Un ejemplo muy interesante lo constituye la denuncia de los miembros del Club Sarmiento de Tucumán en el año 1868, en la que se expresaba que: «...el gobierno ha llamado individualista a los jefes y oficiales de la Guardia Nacional de la Provincia para que trabajen por la candidatura de Elizalde bajo pena de destitución de sus respectivos empleos... Esta pena ha sido aplicada a los Comandantes de batallón Isaías Padilla, Napoleón Maciel... sin más causa que la de pertenecer al club Sarmiento» ${ }^{39}$. En el contexto de la misma elección, las manipulaciones de los jefes militares de la Guardia no dejaron de hacerse presentes, reproduciendo viejas prácticas de los comandantes milicianos. Isaías Padilla, jefe depuesto del batallón de guardias nacionales del departamento de Lules, recolectó y secuestró todas las boletas de enrolamiento de los miembros del batallón de guardias nacionales que dirigía y de esta manera, estos ciudadanos no pudieron emitir su voto. Es decir, aquel documento que era fundamental para el desarrollo del acto electoral permanecía en manos de los Jefes de la Guardia muy ligados a las rencillas políticas y a los enfrentamientos partidarios. De esta manera, un dispositivo central del proceso comicial, la boleta de enrolamiento, pareció someterse al juego político al que estuviera ligado el jefe militar de turno. Además de las boletas de enrolamiento, los jefes de la Guardia contaban con un instrumento más, el armamento de su batallón o regimiento ${ }^{40}$. En el caso que relatamos, Padilla no devolvió al gobierno el total de armamento que, como ex comandante de guardias nacionales, tenía en su poder. Finalmente,

38 Archivo Histórico de Tucumán, Sección Administrativa, 1865, vol. 97, f. 377 . El círculo Campo-Posse, que controló la política provincial entre 1862 y 1867 demostró un importante avance sobre los altos escalafones de la Guardia Nacional. Macías, 2011.

${ }^{39}$ Archivo Histórico de Tucumán, Archivo de la Honorable Legislatura, caja $n^{\circ}$. 20, expediente $\mathrm{n}^{\circ}$. 1458. Macías, 2011.

${ }^{40}$ Para el análisis de otros casos en la campaña bonaerense: Ratto, 2011. Quijada, 2011. Canciani, 2012a. 
con estas herramientas y la reunión de varios adeptos organizó una revolución que fue desmantelada previo a su estallido pero cuya justificación fue la de los abusos de un gobierno que encarcelaba ciudadanos y destituía jefes militares de la Guardia que no fueran adeptos a la lista oficial ${ }^{41}$.

Como demostramos, la Guardia ingresó en el juego político y electoral de las distintas provincias, pero en muchos casos lo hizo al amparo de sus principios fundacionales. Nos referimos a las revoluciones cívico militares legitimadas en el principio de ciudadanía en armas. La custodia de la república, sus instituciones y sus leyes alcanzaban también la salvaguarda de los comicios frente a gobiernos o partidos que pusieran en juego su legitimidad. En ese marco, la Guardia Nacional y la práctica revolucionaria estrecharon fuertes vínculos y en el centro de esta relación estuvo el ciudadano en armas, cuyos atributos se definieron a través de la nueva institución militar ${ }^{42}$. La Guardia terminó por establecer una relación directa entre el ciudadano y la Constitución que superaba tanto el estricto referente local, provincial y personal -materializado en la figura del comandante y de las tradicionales milicias- como el vínculo y subordinación al gobierno de turno. Si bien los levantamientos cívico militares organizados desde la Guardia no dejaron de asociarse en las diferentes provincias a conflictos políticos e inter-partidarios, se incorporaron a la vida republicana como una práctica legítima y vinculada con los comportamientos y los deberes/derechos ciudadanos, que asimismo se relacionaban con el compromiso cívico de custodia de las instituciones, en particular de las elecciones. Veamos, por ejemplo, lo ocurrido en Tucumán en el año 1867, luego de los comicios para gobernador ${ }^{43}$. El Club del Pueblo, que aglutinaba a los opositores al gobernador electo Wenceslao Posse, acusó a este y su círculo de nepotismo y «exclusivismo» así como de obturar toda vía de acción política a aquellos partidos no allegados al suyo. Luego de esta elección victoriosa -la tercera del círculo Campo-Posse desde el año 1862el Club del Pueblo combinó sus acciones con las del Batallón Belgrano de guardias nacionales (batallón más antiguo y selecto de la ciudad capital) y algunos miembros del Ejército asentados en Tucumán y lideraron una revolución. Los argumentos invocaron los principios de la Guardia Nacional y de la ciudadanía en armas ligados con el resguardo de la república y sus leyes y la toma de las armas -si era necesario- para hacerlo efectivo. El levantamiento y la presión de los miembros del mencionado Club aglutinados en el Batallón

\footnotetext{
${ }^{41}$ Archivo Histórico de Tucumán, Sección Administrativa, vol. 104, f. 450-516.

42 Véase Sabato, 2008.

${ }_{43}$ Otros ejemplos para otras provincias en Sabato, 2003. Bragoni y Miguez, 2010, Cucchi, 2015.
} 
Belgrano hizo efectiva la renuncia del gobernador: «El movimiento popular operado en contra de mi autoridad en esta capital el día 30 del próximo junio me ha convencido que no tengo medios para dominarlo estando la opinión del país uniformada por la terminación de mi gobierno... y yo no puedo continuar en su ejercicio cuando tengo convicción de la imposibilidad de mis votos... no es que yo mire en el movimiento un obstáculo insuperable... puesto que las fuerzas de la provincia no podrán resistir a las de la nación... es que una manifestación tan general y espontánea de la voluntad del pueblo me impone el deber de acatarla... luego ante la H. Sala de Representantes, renuncio indeclinablemente de mi cargo de gobernador.... ${ }^{44}$. Traemos aquí este ejemplo ya que nos interesa señalar que, además del derecho a voto, el enrolamiento abría la posibilidad del ejercicio de otro derecho, esto es, el de armarse en defensa de la república y su constitución si estas fuesen violentadas por algún gobierno. Esta directa relación entre el deber de enrolamiento y el ejercicio de derechos políticos terminó por pautar una noción de ciudadanía en la que la Guardia Nacional desempeñó un rol esencial.

\section{Un VÍNCULO A DEBATE}

Con las presidencias de Sarmiento (1868-1874) y Nicolás Avellaneda (1874-1880) se iniciaron una serie de debates y reformas en relación a la Guardia Nacional y su desempeño en la vida electoral. El compromiso de enrolamiento como deber ciudadano nunca se puso en duda, tal como lo afirmaba Sarmiento en un artículo de El Nacional del 14 de noviembre de 1878: «Un ciudadano usará o no de sus derechos políticos, acudiendo o no registrar su nombre en el censo electoral, votando o no en las elecciones. (Sin embargo) no le es facultativo servir o no en la Guardia Nacional. A los dieciocho años ha de estar inscripto en ella y en todo tiempo en adelante estando sujeto por la omisión delincuente a marchar inmediatamente y sin entrar en el sorteo a ocupar su lugar en las filas del Ejército de Línea. Las autoridades deben ser inflexibles en este punto. El enrolamiento es moralizador. Es el primer acto en que el hombre reconoce su dependencia de la sociedad.... Hoy está regularizado el servicio en la Guardia Nacional y su organización es la base del Ejército de Línea. Es pues de todo punto indispensable que no sea minada la institución, introduciendo o permitiendo que nadie se substraiga a formar parte de ella. Los que intentaren hacerlo hallarán su escarmiento en la certidumbre de no escapar al servicio obligatorio como los que cumplieren

\footnotetext{
${ }^{44}$ Cordiero y Viale, 1915, tomo III: 431.
} 
con el deber tradicional cuentan con la ventaja de no ser llamados sino a la suerte (sorteo) cuando hayan de requerirse sus servicios» ${ }^{45}$. Sin embargo, se plantearon desacuerdos, desde su presidencia, en relación al vínculo entre este compromiso cívico y el ejercicio de derechos, en especial el de sufragar. Para Sarmiento, el enrolamiento en la Guardia era un deber directamente vinculado con el potencial servicio en el Ejército de Línea, que nada tenía que ver con el ejercicio de los derechos electorales ${ }^{46}$. En primer lugar, se intensificaron los límites impuestos al Ejercito de Línea en relación con el terreno electoral. En 1873, Sarmiento propuso analizar los comportamientos de los jefes militares en relación con la acción política, profundizar los castigos para aquellos que hacían uso de su rango con fines partidarios y catalogar a estos delitos como «delitos civiles». Todo esto se planteó siguiendo el ejemplo de la ley sancionada en Estados Unidos en 1865: «Una declaración semejante de nuestra ley bastaría para contener abusos que la autoridad no puede estorbar, porque disimulándose con necesidad de servicio militar y cohonestada la iniciativa con los derechos del ciudadano, escapan a todo procedimiento bajo el imperio de las ordenanzas militares, y si en el calor con que los hombres toman las cuestiones políticas el temor de las penas no sería siempre eficaz en los militares, el sentimiento del honor es demasiado activo, y el temor de ser condenados por jueces civiles a perder sus grados, los contiene en el límite del deber, una vez que la ley los haya determinado claramente... El Poder Ejecutivo... pide al Honorable Congreso una ley... que tenga por objeto contener los desmanes de los que armados por la ley en defensa de las instituciones, quieran hacer servir a sus propósitos personales o de partido el poder, la intimidación o la fuerza que las armas dan» ${ }^{47}$. Años después, en los debates en torno a la Ley electoral de 1877 se expuso la gravedad atribuida a este tipo de comportamientos ejercidos por jefes militares y se explicó que el uso político de su cargo implicaba una doble falta: por un lado, «se violaban los deberes del jefes militar como tal»; por otro, «se atentaba contra las libertades públicas» ${ }^{48}$. La posterior reforma de la Ley Electoral en ese año especificó las penas según el caso ${ }^{49}$.

\footnotetext{
45 Sarmiento, 1899, tomo XXXI: 310-311.

46 Ibidem: 302-311.

47 Ibidem: 339-341.

48 Diario de Sesiones, Archivos Legislativos, Honorable Senado de la Nación, 1877, f. 390-395.

49 Por una parte, la transgresión a la prohibición de citación de milicias en el día de la elección implicaba una pena de un mes y medio de prisión o una multa de $\$ 300$. A su vez, la inobservancia del mandato para los jefes de Línea y de la Guardia Nacional de retirarse del recinto de las asambleas electorales una vez emitido su sufragio y no encabezar grupos de
} 
La relación entre la Guardia Nacional y las elecciones constituyó, por su parte, una central preocupación para Sarmiento y un importante motivo de debate público. En las sesiones de la Cámara de Diputados de la Nación del año 1873, uno de los principales puntos en discusión fue el requisito de estar enrolado en la Guardia para poder votar. Aquellos que defendían una directa vinculación entre el deber de enrolamiento y el derecho a voto consideraban que el servicio de armas y el ejercicio del sufragio eran dos componentes inherentes e indisociables de la ciudadanía, a la vez que planteaban una relación directa entre deberes y derechos ciudadanos. Otros, sostenían que esa exigencia constituía un obstáculo para el votante y una herramienta de manipulación electoral que promovía prácticas corruptas y corrompía, asimismo, a la Guardia Nacional ${ }^{50}$. Se oponían, asimismo, entre el cumplimiento del deber de enrolamiento en la Guardia y el efectivo ejercicio de derechos políticos. Más allá de los resultados en el terreno de las practicas, ambas posturas manifestaban la tensión entre dos maneras de comprender a la ciudadanía: por una parte, aquella que consideraba el enrolamiento como un componente casi natural y necesario de la misma, cuya ausencia se asociaba a la carencia de una virtud -el patriotismo- y ponía en cuestión la vigencia de derechos ciudadanos, en particular el sufragio. Por otra, la que concebía al ciudadano como el votante cuyo compromiso patriótico, el de enrolarse en la Guardia, constituía un deber inherente a la esfera militar que nada tenía que ver con el ejercicio de un derecho, el del sufragio y mucho menos el de levantarse en armas «en defensa de la república». Si bien la reforma de 1873 mantuvo el requisito de estar enrolado en la Guardia para poder votar, la de 1877, ya en tiempos de la presidencia de Nicolás Avellaneda (1874-1880), marcó un decisivo cambio: se eliminó el mencionado requerimiento. En contraste con el año 73, los debates previos a la reforma de 1877 sobre este tema fueron poco abundantes y la discusión no tomó mucho tiempo ni ocupó muchas páginas ${ }^{51}$. Sin embargo la decisión se coordinó con las nuevas valencias asignadas ya desde la presidencia de Sarmiento al Ejército Nacional, a las fuerzas de línea y a la noción de ciudadanía en armas. Sarmiento reformuló los sentidos atribuidos a este concepto. Durante su presidencia, se resaltó la importancia de la Guardia a la que consideraba el «genuino ejército de la nación» que se distinguía de la herencia miliciana de

ciudadanos durante el acto electoral se castigaba con una multa de \$100 o un mes de prisión. Más adelante, en el año 1879 se incluyó una modificación más: se prohibieron los ejercicios doctrinales de la Guardia durante el período de inscripción en el Registro Cívico y ocho meses antes de la elección de electores de Presidente.

${ }^{50}$ Navajas, 2014.

${ }^{51}$ Diario de Sesiones, Archivos Legislativos, Honorable Senado de la Nación, 1877, f. 390-395. Navajas, 2014. 
la primera mitad del siglo XIX: «...la obligación y la necesidad de defender la propiedad y la vida, cuando son atacadas, o la integridad y el honor nacional reposan sobre cada individuo de la sociedad, cualquiera sea la forma de gobierno. Las poblaciones nuevas de esta y la otra América se armaron desde el primer día de su existencia para defenderse y sólo cuando se constituyeron las naciones hicieron de esa defensa local un sistema de defensa común llamándole Guardia Nacional. El ejército regular puede suprimirla o exonerarla; pero toda vez que aquel no esté en proporción con la necesidad, la universalidad de los ciudadanos constituye el ejército nacional... Toda limitación que ponga el poder nacional sobre el uso de la guardia nacional es suicidar la nación y hacer nacer por fuerza lo que con tantos sacrificios destruimos o neutralizamos entre todos, a saber: las milicias que con Ramírez y Quiroga sublevaron el país y mantuvieron la guerra constante en las provincias... La guerra civil de cincuenta años fue sólo la antigua milicia localizada bajo un caudillo» ${ }^{52}$.

Para Sarmiento, la Guardia Nacional constituía la versión «moderna y civilizada» de las antiguas milicias provinciales ya que teóricamente el ciudadanoguardia nacional era el individuo que había desarrollado un vínculo directo con la nación por sobre los referentes locales-personales. En ese marco, la defensa de la propiedad privada, del trabajo propio y de los frutos de ese trabajo era una tarea esencial de los «ciudadanos-guardias nacionales». Para Sarmiento, la defensa de la nación atribuida a los individuos implicaba el resguardo del orden público y este orden sólo podía lograrse mediante la dedicación al trabajo y a la vida política y no mediante la permanente movilización armada de la ciudadanía que ponía en vilo la política y promovía la violencia. Por lo tanto, durante su presidencia definió a la Guardia como una institución «moderna» compuesta por ciudadanos «trabajadores», «industriosos» y «libres». La exaltación del componente «cívico» del Guardia Nacional y el afianzamiento del referente nacional materializado no sólo en la constitución sino también en el propio poder central, se constituyeron en garantías de estabilidad y de orden frente a la importante militarización que hasta ahora había evidenciado la vida pública, en particular los procesos electorales: «Tiempo es ya de que el soldado argentino se parezca al de norteamérica, mostrándose siempre ciudadano, hombre laborioso y sostenedor de la tranquilidad pública» ${ }^{53}$. Según Sarmiento, la Guardia debía afianzarse como fuerza de reserva, como institución que mediante su organización y enrolamiento informaba a la nación sobre los potenciales soldados-ciudadanos y no de los 2014

${ }^{52}$ Citado en Oszlak, 1997: 178 (nota 23). Este tema se aborda en profundidad en Macías,

${ }^{53}$ El Nacionalista, Tucumán, 23 de Enero 1870. Sobre la caracterización de los procesos electorales como verdaderos «combates» véase Sábato, 1998. 
potenciales votantes. Todo guardia nacional era, en realidad, un posible soldado de línea que accedía a este servicio mediante su enrolamiento en la Guardia y el posterior mecanismo del sorteo. La movilización de esta fuerza como estricta incumbencia del poder central fue constantemente exaltada por Sarmiento. Hasta que ocurriera este llamado, el ciudadano-guardia nacional debía dedicarse a sus actividades económicas, civiles y políticas y su enrolamiento no debía en ningún caso determinar el ejercicio de su derecho a votar.

A partir de 1877 y de la reforma electoral de ese año, la presencia de la Guardia fue formalmente limitada en la vida electoral tanto por la anulación del requisito de estar enrolado en la misma para poder emitir sufragio como por la explícita prohibición de que los guardias nacionales movilizados pudiesen votar. De esta manera, se clausuraba formalmente una de las vías que jefes militares y gobiernos habían utilizado para manipular al electorado: el enrolamiento militar y las boletas que lo acreditaban. En consonancia con estas resoluciones, los Departamentos de Policía de las provincias se burocratizaron y adquirieron fuerte presencia en la administración y mantenimiento del orden público, desplazando a la Guardia Nacional de estas funciones. Por otra parte, el enrolamiento en la Guardia pasó a ser una tarea que formalmente desempeñaron comisiones de civiles citadas para tal fin y dejó de estar en manos de los jefes militares ${ }^{54}$. Estos cambios no desterraron muchas de las prácticas o principios previos, sobre todo aquellos ligados a revoluciones amparadas en los principios de la ciudadanía en armas, que se mantuvieron en algunos

${ }^{54}$ A partir de la Reforma de 1877 los reglamentos provinciales incorporaron explícitamente la prohibición de votar de los guardias nacionales en ejercicio (véase Macias, 2014. Cucchi, 2015). A la prohibición de citar milicias y de llevar armamento así como de utilizar la jefatura militar para coartar la libertad de sufragio, acudir con agrupaciones de ciudadanos a sufragar y permanecer en el recinto electoral más tiempo del que implicaba sufragar se sumó algo más: la fuerza movilizada que no fuese un cuerpo de policía especialmente convocado para mantener el orden en los comicios debía permanecer acuartelada mientras dure el proceso electoral. Se explicitó que quedaba prohibido que sargentos, cabos y soldados del Ejército de Línea y de la Guardia Nacional movilizada votasen. Los altos rangos de ambas fuerzas podían hacerlo pero bajo las condiciones ya enunciadas. Igualmente, quedaba dispuesta la prohibición a cualquier individuo de presentarse con armas o milicias a las asambleas electorales. Mediante esta Ley se explicitó el requerimiento de estar inscripto en el Registro Cívico para poder votar «sin que la boleta de calificación sea necesaria para la emisión del voto». A su vez, el artículo $36^{\circ}$ especificaba que «al lado de cada mesa existiría colocada en un cuadro, a la vista del pueblo, la serie correspondiente del Registro para hacer las verificaciones a que haya lugar». Por último, un dato de sumo interés fue la determinación de quiénes no podían inscribirse en el Registro Cívico. Además de los que carecieran de la edad requerida y de los sordo-mudos que no supieran leer ni escribir, no podían inscribirse «los soldados, cabos y sargentos de la Gendarmería Provincial así como de la tropa de línea de la nación». Ley de Elecciones de Tucumán, 1883, Sánchez y De Moral, 1915, vol. IX: 359-363. 
clubes políticos o bien emergieron de manera violenta en acontecimientos como el de la revolución de 1880 en Buenos Aires, la revolución de 1890 o las revoluciones radicales posteriores. Pero dichas reformas constituyeron una manifestación del rumbo que tomó la república -a partir de fines de la década de 1870 - respecto de la Guardia Nacional como fuerza cívico-militar, de la noción de ciudadanía y del ejercicio de los derechos y deberes cívicos. $\mathrm{Y}$ otorgan un interesante marco para interpretar los debates parlamentarios nacionales y aquellos ocurridos en el marco de la opinión pública durante toda la década de 1890, en torno al servicio de armas ciudadano ${ }^{55}$.

\section{REFLEXIONES FINALES}

La reforma electoral de 1863 cristalizó en la esfera institucional y legislativa una noción de ciudadanía en la que la obligación de enrolarse en la Guardia Nacional se planteó como antecedente ineludible del ejercicio del derecho a voto. Los términos de esta relación erigieron al padrón de enrolamiento en un instrumento electoral fundamental que informaba a las autoridades de los potenciales votantes. Pero, asimismo, prefiguraron una noción de ciudadanía en la que el enrolamiento antecedía el ejercicio de todo derecho, en particular el del voto y el de armarse en defensa de la patria y su constitución. Estos principios llenaron de sentido político a la Guardia Nacional y al concepto de ciudadanía armada, y permiten interpretar la particular actuación de esta fuerza en la vida pública.

Pero su materialización en las prácticas políticas dieron lugar a la emergencia de debates y contrapuntos en torno a la relación Guardia Nacionalciudadanía política, que hicieron visible la convivencia de nociones de ciudadanía en tensión: por una parte, aquella que consideraba al enrolamiento como un componente casi natural y necesario de la misma, cuya ausencia se asociaba a la carencia de una virtud -el patriotismo- y ponía en cuestión la vigencia de derechos ciudadanos, en particular el del sufragio; y por otra, la que concebía al ciudadano como el votante cuyo compromiso patriótico, el de enrolarse en la Guardia, constituía un deber inherente a la esfera militar que nada tenía que ver con el ejercicio de un derecho, el del sufragio. En un caso, el padrón de enrolamiento informaba de la ciudadanía en cumplimiento de sus obligaciones esenciales y, por lo tanto, de los potenciales votantes. Aquí la Guardia remitía a un funcionamiento menos dependiente de las decisiones del gobierno de turno y más cercana a los deberes y derechos ciudadanos. En el otro caso, el padrón de enrolamiento daba cuenta de la población ciudadana

${ }^{55}$ Véase Bertoni, 2001. 
dispuesta servir en armas a la nación sometiéndose al sorteo que distinguiría a sus miembros como integrantes del Ejército de Línea. Mientras esto no ocurriese, la custodia de la República se materializaba en el ejercicio del voto, la dedicación al trabajo y la educación, restringiéndose el uso de las armas a las fuerzas regulares y profesionales. Esta última opción, planteada con claridad desde la presidencia de Domingo Faustino Sarmiento, se vinculó de manera directa con el proyecto de profesionalización de las fuerzas armadas, la burocratización de las policías provinciales y la desarticulación de la fórmula guardia nacional-votante que lideró el presidente y que se proyectó durante las décadas del 1870 y 1880 . En ningún caso, la existencia de la Guardia Nacional fue puesta en cuestión.

En el marco del proceso de construcción del Estado nación, su creación se asoció con la opción por la República, abrió el debate sobre la noción de ciudadanía y la defensa armada y puso en juego diferentes formas de concebir y ejercitar los deberes y derechos cívicos.

\section{BiBLIOGRAFÍA}

Annino, Antonio (coord.), Historia de las elecciones en Iberoamérica, siglo XIX, México, Fondo de Cultura Económica, 1995.

Bertoni, Lilia Ana, Patriotas, cosmopolitas y nacionalistas. La construcción de la nacionalidad argentina a fines del siglo XIX, Buenos Aires, Fondo de Cultura Económica, 2001.

Bonaudo, Marta, "Revisitando a los Ciudadanos de la República Posible (Santa Fe 1853-1890)", Anuario del IEHS, 18 (Tandil, 2004): 213-232.

Bonaudo, Marta (dir.), Imaginarios y prácticas de un orden burgués. Rosario, 18501930, T 1, Rosario, Prohistoria, 2005.

Botana, Natalio. El orden conservador. La política argentina entre 1880 y 1916, Buenos Aires, Ed. Sudamericana, 1994.

Bragoni Beatriz y Míguez, Eduardo, Un nuevo orden político. Provincias y Estado nacional, 1852-1880, Buenos Aires, Biblos, 2010.

Bravo, María Celia, "Poder provincial, dinámica regional y Estado nacional. El norte argentino entre 1852-1880", Travesía, Revista de Historia Económica y Social, 1 (Tucumán, 2000): 49-175.

Bravo, María Celia, "La política armada. El proceso de recomposición de la élite política en el norte argentino (1852-1860)", Hilda Sabato y Alberto Lettieri (comps.), La política en la Argentina del siglo XIX, Armas, votos y voces, Buenos Aires, Fondo de Cultura Económica, 2003: 243-258. 
Buchbinder, Pablo, Caudillos de pluma y hombres de acción. Estado y Política en Corrientes en tiempos de la organización nacional, Buenos Aires, Prometeo, 2004.

Campi, Daniel, “Azúcar y trabajo. Coacción y mercado laboral en Tucumán, Argentina, 1856-1896", Tesis Doctoral, Universidad Complutense de Madrid, 2002.

Canciani, Leonardo, "Las Guardias Nacionales en Argentina durante la organización nacional: balances y perspectivas historiográficas", História Unisinos, 16/3 (Rio dos Sinos, 2012): 391-402.

Canciani, Leonardo, "El coronel don José Benito Machado: un comandante de Guardias Nacionales en la frontera sur bonaerense (1852-1880)", Mundo Agrario: Revista de Estudios Rurales, 12/24 (La Plata, 2012a): 1-41.

Cansanello, Carlos, De súbditos a ciudadanos, Buenos Aires, Imago Mundi, 2003.

Carvalho, José Murilo de, Desenvolvimiento de la ciudadanía en Brasil, México, FCE, 1995.

Castro, Jeanne Berrance de, A milicia ciudad: a Guarda Nacional de 1831 a 1850, Sao Paulo, Brasiliana, 1979.

Chust, Manuel y Marchena, Juan (eds.), Las armas de la Nación. Independencia y ciudadanía en Hispanoamérica (1750-1850), Madrid/Frankfurt, Iberoamericana/ Vervuert, 2007.

Cordeiro, Ramón y Viale, Dalmiro, Compilación ordenada de leyes, decretos y mensajes de la Provincia de Tucumán que comienza en el año 1853, vol. I al VIII, Tucumán, Edición Oficial, 1915.

Cucchi, Laura, Antagonismo, legitimidad y poder politico en Córdoba, 1877-1880, Buenos Aires, EdiUNS, 2015.

Deas, Malcolm, "The Role of the Church, the Army and the Police in Colombian Elections, 1850-1930", Eduardo Posada-Carbó, (ed.), Elections before Democracy. The History of Elections in Europe and Latin America, Londres, ILAS, 1997: 163-180.

Di Meglio, Gabriel, ¡Viva el bajo pueblo! La plebe urbana de Buenos Aires y la política entre la revolución de mayo y el rosismo, Buenos Aires, Prometeo, 2006.

Fertig, André Atila, Clientelismo político en tempos belicosos: a Guarda Nacional da Provincia do Sao Pedro do Rio Grande do Sul na defensa do Imperio do Brasil (1850-1873, Santa María, UFSM, 2010.

Fradkin, R., "Notas para una historia larga: comandantes militares y gobierno local en tiempos de guerra", B. Bragoni y E. Míguez (coord.): Un nuevo orden político. Provincias y Estado nacional, 1852-1880, Buenos Aires, Biblos, 2010: 293-306.

Gallo, Ezequiel, Colonos en armas. Las revoluciones radicales en la provincia de Santa Fe (1893), Buenos Aires, Siglo XXI Eds., 2003.

Garavaglia, Juan Carlos et al., Las fuerzas de la guerra en la construcción del Estado: América Latina siglo XIX, Rosario, Prohistoria, 2012. 
Graham, Richard, "Formando un Gobierno Central: Las Elecciones y El Orden Monárquico en el Brasil del Siglo XIX", Antonio Annino (comp.), Historia de las Elecciones en Iberoamérica, Siglo XIX, México, FCE, 1995: 347-380.

Halperín Donghi, Tulio, Una nación para el desierto argentino, Buenos Aires, CEAL, 1982.

Hernández Chávez, Alicia, La tradición del buen gobierno, México, FCE, 1994.

Irurozqui, Marta, A bala, piedra y palo. La construcción de la ciudadanía política en Bolivia, 1825-1952, Sevilla, Diputación de Sevilla, 2000.

Irurozqui, Marta, La ciudadanía en debate en América Latina. Discusiones historiográficas y una propuesta teórica sobre el valor público de la infracción electoral, Lima, IEP, 2005.

Irurozqui, Marta (ed.), La mirada esquiva. Reflexiones históricas sobre la interacción del Estado y la ciudadanía en los Andes (Bolivia, Ecuador y Perú), siglo XIX, Madrid, CSIC, 2005a.

Irurozqui, Marta, Dossier "Violencia política en América Latina, siglo XIX", Revista de Indias, 246 (Madrid, 2009).

Irurozqui, Marta y Galante, Miriam (eds.), Sangre de Ley. Justicia y violencia en la institucionalización del Estado en América Latina, siglo XIX, Madrid, Polifemo, 2011.

Lanteri, María Sol, Un vecindario federal. La construcción del orden rosista en la frontera sur de Buenos Aires (Azul y Tapalqué), Córdoba, Centro de Estudios Históricos Prof. Carlos S. A. Segreti, 2011.

Lobato, Mirta y Venturuoli, Sofía (eds.), Formas de ciudadanía en América Latina, Berlín, AHILA/Iberoamericana Vervuert, 2013.

Macías, Flavia, "De cívicos a Guardias Nacionales. Un análisis del componente militar en el proceso de construcción de la ciudadanía", Manuel Chust y Juan Marchena (eds.), Las armas de la Nación. Independencia y ciudadanía en Hispanoamérica (1750-1850), Madrid/Frankfurt, Iberoamericana/Vervuert, 2007: 263-289.

Macías, Flavia, "Política, Guardia Nacional y ciudadanos en armas. Tucumán, 18621868", Entrepasados, XIX (Buenos Aires, 2011): 31-50.

Macías, Flavia, "Entre la organización nacional, la política y las revoluciones. Las fuerzas militares durante la presidencia de Domingo Faustino Sarmiento (18681874)", Marta Irurozqui y Miriam Galante (eds.), Sangre de Ley. Violencia y justicia en la institucionalización del Estado. América Latina, siglo XIX, Madrid, Ed. Polifemo-GEA, 2011a: 277-300.

Macías, Flavia, "La ciudadanía y su dimensión política en América Latina”, Mirta Lobato y Sofía Venturuoli (eds.), Formas de ciudadanía en América Latina, Berlín, AHILA/Iberoamericana Vervuert, 2013. 
Macías, Flavia, Armas y política en la Argentina, Tucumán, siglo XIX, Madrid, CSIC, 2014.

Macías, Flavia y Parolo, María Paula, "Guerra de independencia y reordenamiento social. La militarización en el norte argentino ( $1^{\circ}$ mitad del siglo XIX)", Ibero Americana, América - España - Portugal, (Berlín, 2010): 19-38.

Macías, Flavia y Sábato, Hilda, "La Guardia Nacional: Estado, política y uso de la fuerza en la Argentina de la segunda mitad del siglo XIX", dossier, Hilda Sábato (coord.), "Historias de la República. Variaciones sobre el orden político en la Argentina del siglo XIX”, POLHIS, 11 (Buenos Aires, 2013): 70-81.

Macías, Flavia y Navajas, María José, "Entre la violencia política y la institucionalización provincial. La revolución de los Posse en Tucumán, 1856", dossier, Flavia Macías (coord.): "Milicias, levantamientos armados y construcción republicana en Hispanoamérica. Estudios y propuestas para el siglo XIX", Boletín del Instituto de Historia Argentina y Americana Dr. Emilio Ravignani, 42 (Buenos Aires, 2015): 92-122.

Malamud, Carlos (coord.), Legitimidad, representación y alternancia en España y América Latina: las reformas electorales (1880-1930), México, FCE, 2000.

Malamud, Carlos y Dardé, Carlos, Violencia y legitimidad política y revoluciones en España y América Latina, 1840-1910, Santander, Universidad de Cantabria, 2004.

Mendez, Cecilia, The Plebeian Republic. The Huanta Rebellion and the Making of the Peruvian State. 1820-1850, Durham and London, Duke Universiy Press, 2005.

Navajas, María José, “Actores, representaciones, discursos y prácticas. La política en Tucumán, Argentina, 1852-1887”, Tesis Doctoral inédita, México, El Colegio de México, 2008.

Navajas, María José, “Las controversias por la reforma electoral argentina, 1873”, Estudios de Historia Moderna y Contemporánea de México, 48 (México, 2014): 39-67.

Oszlak, Oscar, La Formación del Estado Argentino, Buenos Aires, Editorial de Belgrano, 1997.

Parolo, María Paula, "Estructura socio-ocupacional y sectores populares en Tucumán. Primera mitad del siglo XIX”, Tesis Doctoral, Tucumán, UNT, 2003.

Parolo, María Paula, “Juicio, condena y ejecución de Francisco Acosta, 'consentidor de ladrones'. Alcances y límites de los comandantes de campañas en Tucumán a mediados del siglo XIX”, Anuario del IEHS, 23 (Tandil, 2003a): 175-198.

Peralta Ruiz, Víctor, "El mito del ciudadano armado. La "semana magna" y las elecciones de 1844 en Lima”, Hilda Sábato (coord.), Ciudadanía política y formación de las naciones. Perspectivas históricas en América Latina, México, FCE, 1999: 231-252.

Posada Carbó, Eduardo, Elections before Democracy. The History of Elections in Europe and Latin America, Londres, ILAS, 1997. 
Quijada, Mónica (ed.), De los cacicazgos a la ciudadanía. Sistemas politicos en la frontera. Río de la Plata, siglos XVIII-XX, Berlín, Iberoamericana, 2011.

Ratto, Silvia, "Guardias nacionales en las fronteras de Buenos Aires durante la década de 1850", Guerra, violencia y construcción del Estado. América latina, siglo XIX, Actas de Congreso, San José, Ciapa, 2011.

Registro Oficial de la República Argentina, Buenos Aires, Edición Oficial, 1883.

Sabato, Hilda, La política en las calles. Entre el voto y la movilización, Buenos Aires, 1862-1880, Buenos Aires, Sudamericana, 1998.

Sabato, Hilda, Ciudadanía política y formación de las naciones. Perspectivas históricas de América Latina, México, FCE, 1999.

Sabato, Hilda, "El ciudadano en armas. Violencia política en Buenos Aires, 18521890”, Entrepasados, 23 (Buenos Aires, 2003): 149-169.

Sabato, Hilda, Buenos Aires en armas. La revolución de 1880, Buenos Aires, Siglo XXI, 2008.

Sabato, Hilda, Historia de la Argentina, 1852-1890, Buenos Aires, Siglo XXI, 2012.

Sabato, Hilda (coord.), "Historias de la República. Variaciones sobre el orden político en la Argentina del siglo XIX", POLHIS, 11 (Buenos Aires, 2013).

Sabato, Hilda y Lettieri, Alberto (comps.), La política en la Argentina del siglo XIX, Armas, votos y voces, Buenos Aires, FCE, 2003.

Sabato, Hilda; Ternavasio, Marcela; De Privitelio, Luciano y Persello, Ana Virginia, Historia de las elecciones en la Argentina -1805-2011, Buenos Aires, Editorial El Ateneo, 2011.

Sánchez Loria, Horacio y De Moral, Ernesto, Compilación ordenada de leyes, decretos y mensajes de la Provincia de Tucumán que comienza en el año 1853, vol. IX, Tucumán, Edición Oficial, 1915.

Sarmiento, Domingo Faustino, Obras completas, Buenos Aires, Imprenta y Litografía Mariano Moreno, 1899.

Schmit, Roberto, Ruina y resurrección en tiempos de guerra. Sociedad, economía $y$ poder en el oriente entrerriano postrevolucionario, 1810-1852, Buenos Aires, Prometeo, 2004.

Sobrevilla, Natalia, “'Ciudadanos armados': las Guardias Nacionales en la construcción de la nación en el Perú de mediados del siglo XIX”, Manuel Chust y Juan Marchena (eds.), Las armas de la nación. Independencia y ciudadanía en Hispanoamérica (1750-1850), Madrid/Franckfurt, Iberoamericana/Vervuert, 2007: 159-184.

Ternavasio, Marcela, La revolución del voto. Política y elecciones en Buenos Aires, 1810-1852, Buenos Aires, Siglo XXI, 2002. 
Ternavasio, Marcela, Historia de la Argentina, 1806-1852, Buenos Aires, Siglo XXI Editores, 2009.

Tío Vallejo, Gabriela, Antiguo Régimen y Liberalismo, 1770-1830, Tucumán, UNT, 2000.

Thomson, Guy, "Bulwarks of Patriotic Liberalism: The National Guard, Philharmonic Corps and Patriotic Juntas in Mexico, 1847-88", Journal of Latin American Studies, 22/1 (Londres, 1990).

Fecha de recepción: 20 de septiembre de 2015.

Fecha de aceptación: 2 de febrero de 2016.

\section{The Duty of Enlisting and the Right to Vote. Reflexions On Armed Citizenry and Suffrage in Argentina, 1863-1877}

This paper reflects on one of the key subjects in nineteenth-century Spanish-American politics: the role of civil-military forces, particularly the National Guard, in the electoral process and its effects on the creation of political citizenry. Special attention is paid to Argentina in the 1860s and 1870s, exploring how the laws and institutions defined and specified the relationship between enlisting in the National Guard and exercising the right to vote. This is done by studying the legislative debates that took place prior to the National Electoral Law of 1863 coming into effect, as well as those pertaining to the electoral reforms of 1873 and 1877 , in addition to the changes in electoral legislation and the influence of Domingo Faustino Sarmiento's thoughts on the aforementioned processes.

KeY WORDS: National Guard; elections; citizens at arms; Republic. 